\title{
Radiological evaluation of anterior lumbar fusion using PEEK cages with adjacent vertebral autograft in spinal deformity long fusion surgeries
}

\author{
Jianqiang Ni $\cdot$ Yanping Zheng $\cdot$ Ning Liu $\cdot$ \\ Xin Wang $\cdot$ Xiutong Fang $\cdot$ Rishabh Phukan • \\ Kirkham B. Wood
}

Received: 17 September 2014/Revised: 25 December 2014/Accepted: 25 December 2014/Published online: 25 January 2015

(C) The Author(s) 2015. This article is published with open access at Springerlink.com

\begin{abstract}
Purpose The aim of this study was to evaluate the radiographic characteristics of polyetheretherketone (PEEK) cages packed with adjacent vertebral autograft material in lumbar anterior lumbar interbody fusion (ALIF) in spinal deformity long fusion surgeries.

Methods This is a retrospective radiographic study. From April 2008 to April 2012, 40 patients (5 males and 35 females, mean age $67 \pm 9$ years) with coronal and/or sagittal spine deformities underwent staged corrective surgery combined with lumbar ALIF using PEEK cages at the L3-L4, L4-L5 or L5-S1 segment with posterior long ( $\geq 4$ levels) instrumentation. The mean follow-up time was 27.5 months (13-49 months). We examined the interbody fusion rate and cage subsidence at 3 months postoperatively and final follow-up. Additionally, we evaluated the distance of cage migration at final follow-up and the improvement in lumbar lordosis. The rate of "collapse" of the adjacent vertebra where the autograft was harvested
\end{abstract}

J. Ni and Y. Zheng contributed equally to the manuscript.

J. Ni · Y. Zheng

Department of Orthopedics, Qilu Hospital, Shandong University,

Shandong, China

J. Ni $\cdot$ X. Wang

Department of Orthopedics, Yuhuangding Hospital, Shandong, China

J. Ni · N. Liu · R. Phukan · K. B. Wood ( $\square)$

Department of Orthopedics, Massachusetts General Hospital,

Harvard Medical School, Boston 02114, MA, USA

e-mail: KBWOOD@mgh.harvard.edu

X. Fang

Department of Orthopedics, Beijing Shijitan Hospital Affiliated Beijing Capital Medical University, Beijing, China was assessed at the final follow-up. Finally, we examined the cage-related postoperative complications in this series. Results Solid interbody fusion was achieved in $96.4 \%$ (81/84) of the levels at the final follow-up. A mild forward cage migration was observed, and the mean migration distance at final follow-up was $0.83 \mathrm{~mm}$ in $\mathrm{L} 3 / 4,0.36 \mathrm{~mm}$ in $\mathrm{L} 4 / 5$ and $0.55 \mathrm{~mm}$ in L5/S1. There was cage subsidence observed in $8.3 \%(7 / 84)$ of the levels. In all patients, the PEEK cage maintained a significant increase in segmental lordosis at all postoperative visits. However, a mild reduction in segmental lordosis still occurred with time. The adjacent lumbar vertebral bodies where the autografts were harvested appeared to be intact in height radiologically at the final follow-up. There were no postoperative complications due to bone harvesting or cage insertion. Proximal junctional kyphosis was found in one patient who underwent a subsequent revision surgery.

Conclusions The use of lumbar ALIF with PEEK cages and adjacent vertebral autografts in spinal deformity long fusion surgeries is an effective and safe procedure. The allograft filler is safe and effective in maintaining the shape of harvested vertebrae. Additional long-term follow-up studies are needed to further justify its use.

Keywords Adult spine deformity - PEEK cage - Local vertebral autograft $\cdot$ Cage migration

\section{Introduction}

Anterior lumbar interbody fusion (ALIF) is an established treatment for structural instability associated with symptomatic disc degeneration. Despite numerous advantages, ALIF with a bone graft as a stand-alone procedure is associated with high rates of non-union (44\%) [1], subsidence, 
and graft extrusion. These complications are due to insufficient stability for vertebral interbody fusion [2,3]. A combined anterior and posterior approach is often the preferred option, especially for adult spine deformity correction with severe low lumbar curvatures [4]. Femoral ring allografts (FRAs) packed with autograft bone and combined with posterior instrumentation have shown promising fusion rates and sagittal lordosis restoration in spine deformities. This approach also avoids donor site morbidity $[3,5]$. However, the bones are less stable at the endplate interface and often require supplemental anterior or posterior fixation $[6,7]$.

Many ALIF PEEK cages are being used widely nowadays. The SynFix- $\mathrm{LR}^{\mathrm{TM}}$ is a relatively new one that satisfies the biomechanical requirements for an interbody fusion device [8]. It is made of a non-absorbable biocompatible polyetheretherketone (PEEK) material that is radiolucent and has a modulus of elasticity similar to bone $[9,10]$. The use of PEEK cages offers advantages over metal cages in load bearing and may reduce the subsidence rate. Furthermore, due to its radiolucency, the interbody cages made of PEEK permit assessment of fusion in radiographs $[11,12]$. Previous studies reported high fusion rates and acceptable clinical outcomes using these cages in the treatment of lumbar spondylolisthesis [13] and lumbar degenerative disc disease [14].

ALIF using PEEK cages has been reported in the treatment of adult spinal deformities in conjunction with posterior pedicle screw fixation $[15,16]$. However, assessments such as the fusion rate, subsidence rate, cage migration, and the evaluation of harvested vertebrae have not been clearly documented in PEEK cages with local vertebral autografts in long fusions.

Locally harvested vertebral body bone was used in our study to fill interbody cages, which avoids both the cost of bone graft substitutes and the morbidity of iliac crest bone graft retrieval. The objectives of this study were to radiographically evaluate the utility of PEEK cages packed with local vertebral autografts in the anterior lumbar intervertebral space during spinal deformity long fusions of the lumbosacral spine. We hypothesize that the locally harvested lumbar body bone will have a better fusion rate. Furthermore, we hypothesize that removing a sufficient amount of bone from the anterior aspect of the adjacent lumbar spine will not weaken the vertebral body significantly. There are no previous studies examining these outcomes.

\section{Materials and methods}

\section{Study population}

We retrospectively reviewed 68 consecutive adult patients with global coronal and sagittal spine deformities treated with combined long posterior fusions to the sacrum or ilium and ALIF using PEEK cages between 2008 and 2012. Standing neutral lateral radiographs were obtained. The inclusion criteria were: (1) age older than 18 years, (2) patients with spine deformities including scoliosis, kyphosis and flat-back, who underwent ALIF with PEEK cage at L3L4, L4-L5 and/or L5-S1. The exclusion criteria were: (1) follow-up time less than 1 year postoperatively. (2) Inadequate or missing radiography. (3) Osteotomy procedure at lumbar spine. (4) Previous fusion to the sacrum. Patients with a medical condition affecting bone healing (e.g. diabetes mellitus) were excluded from the study. Finally, 40 consecutive patients were included (Figs. 1, 2, 3).

An anterior retroperitoneal approach was used for ALIF during the first stage of a two-stage procedure. The patients were placed in the supine position. The spine was approached retroperitoneally through a midline incision. A senior spine surgeon exposed the anterior surface and lateral borders of the disc space. The anterior longitudinal ligament was incised. The scalpel blades were used to remove disc material from both endplates and the posterior annulus to effectively decompress and mobilize the disc spaces. The next step was to introduce autologous bone that was harvested from the adjacent vertebral bodies. The harvested bone was placed into the three compartments of the intervertebral cage before implantation. The cage was inserted and fixed with one to four 20-25-mm cortical screws. Each donor vertebra was packed with corticocancellous allograft from the Synthes Corporation. A powdered gelfoam was used for haemostasis. All patients underwent posterior fusion to the sacrum or ilium using pedicle screw systems during the second stage of surgery. We implanted 12 SynFix-LR PEEK cages (Synthes) for 7 patients, $61 \mathrm{~K} 2 \mathrm{M}$ Chesapeake ${ }^{\mathrm{TM}}$ PEEK cages for 27 patients and 11 Globus PEEK cages (Globus Medical, Audubon, PA, USA) for 6 patients.

\section{Radiographic measurements}

Upright standard lateral digital radiographies were measured at different intervals. The radiographs were used to measure four parameters. (1) The height of the harvested lumbar vertebral body was measured. (2) We evaluated segmental lordosis, which is defined as the angle between the upper endplate of the cranial vertebrae and the lower endplate of the caudal vertebra. T12-S1 represented all of the lumbar lordosis. These regions were measured preoperatively and immediately postoperatively. The measurements were repeated at 3 months and at the final visit. (3) Evaluation of PEEK cage migration. We measured the distance from the anterior rim of the PEEK cages to the anterior margin of the vertebra. (4) The disc height was measured as the distance between the middle points of the vertebral endplates. 
Fig. 1 Spinal radiographs of L3-S1 K2M Chesapeake ${ }^{\text {TM }}$ PEEK cages ALIF fusion with posterior long fusion (T1-S1), showing solid interbody fusion of L3-S1
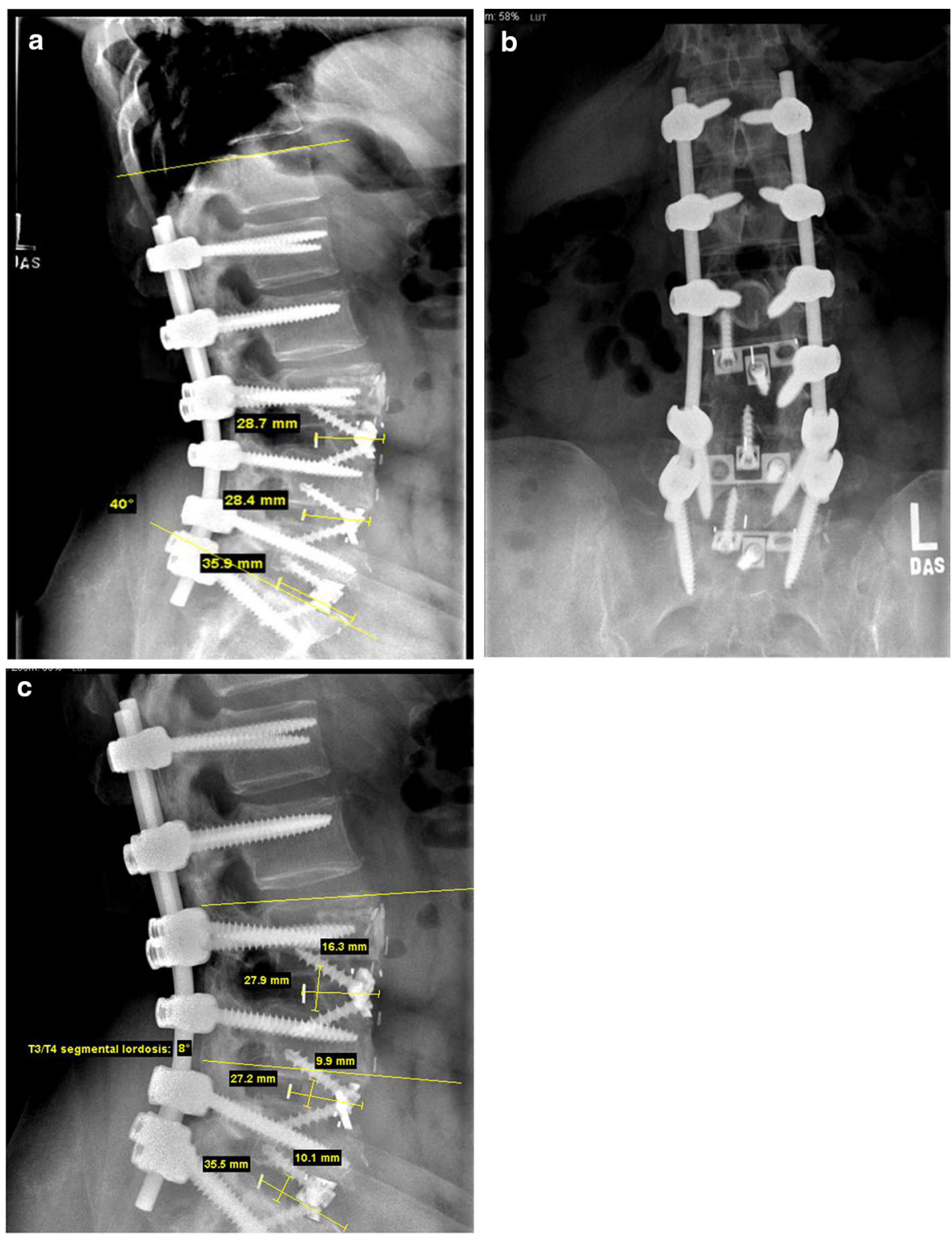

The fusion was assessed based on the following criteria: lack of substantial sclerotic changes in the recipient bone bed [17], visible bridging bone either through the cage or surrounding it as observed on anterior-posterior or lateral radiographs [18], and vertebral body translation of $<3 \mathrm{~mm}$ on lateral radiographs [19]. A thin layer slicing CT scan was performed in all cases where bone fusion on plain radiographs was in doubt (CT scan was performed in 8 patients). Subsidence was assessed based on the following criteria: disc space height loss of $>1 \mathrm{~mm}$ (indicating cage protrusion into the cancellous vertebral bone) and visible fracture of the vertebral body endplate [17].
Statistical analysis

All of the continuous parameters are presented as the mean and standard deviation (SD) with $95 \%$ confidence intervals (CI). The categorical parameters are described with proportions and $95 \%$ confidence intervals. The comparisons of outcome between two different intervals were performed using two-tailed unpaired $t$ tests for continuous parameters. The statistical analyses were performed using SPSS for Windows (version 16.0; IBM, Chicago, IL, USA). The significance level was set at $p<0.05$. 


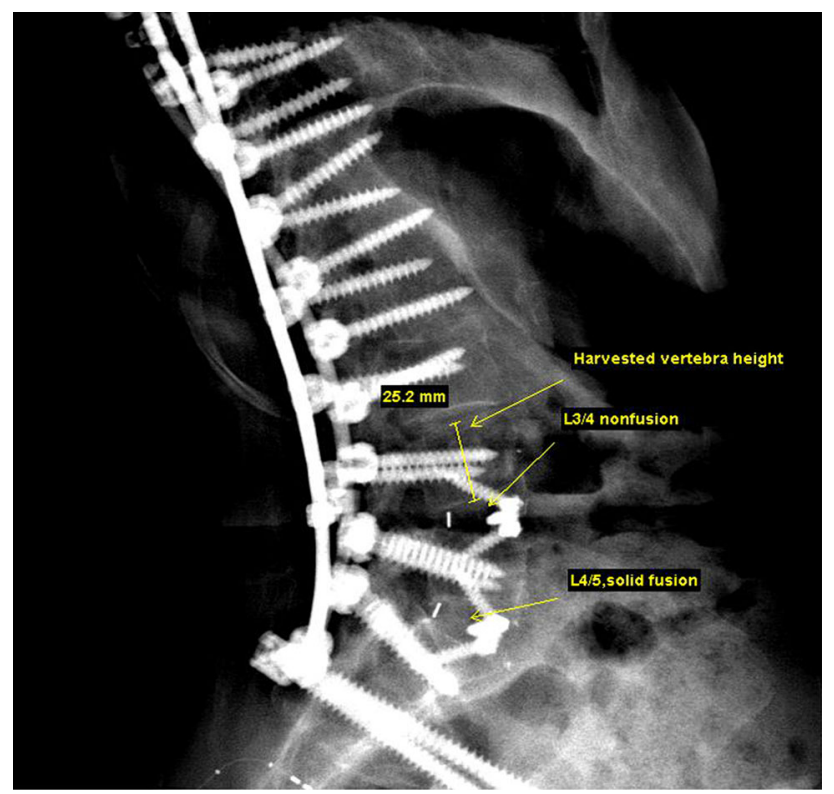

Fig. 218 months postoperative lateral radiograph showed that L5S1 got a solid fusion, while L4-L5 level showed non-union

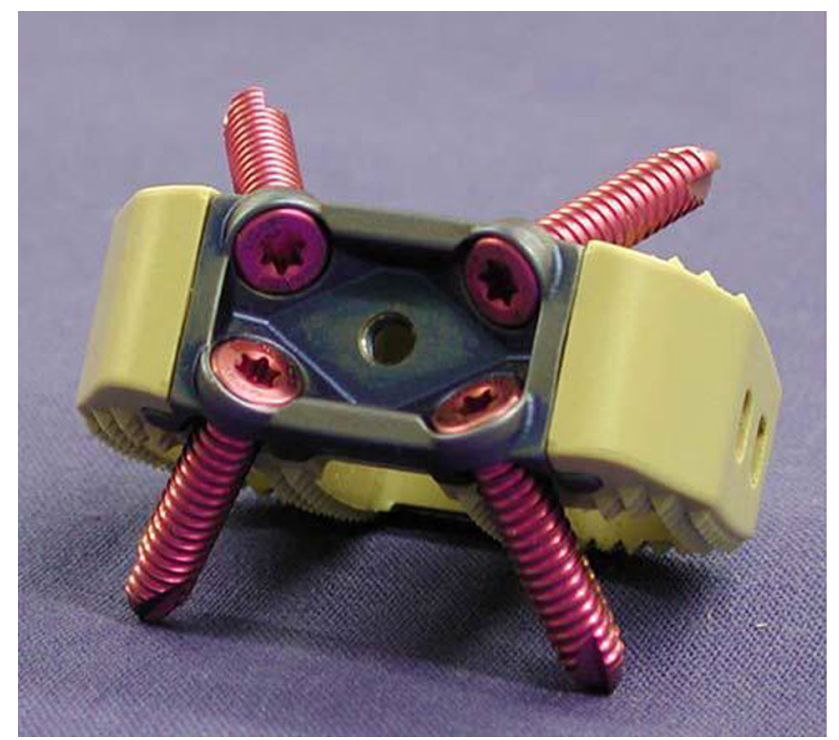

Fig. 3 SynFix; anterocaudal view with locking screws inserted

\section{Results}

Forty patients met all study criteria and were available for data analysis. The mean patient age was 67 years (range 49-79 years). The mean final follow-up was 27.5 months (range 13-49 months). There were 35 females (87.5\%) enrolled in this study. The mean body mass index (BMI) was $26.4 \mathrm{~kg} / \mathrm{m}^{2}$, and 7 patients were classified as obese (BMI $>30 \mathrm{~kg} / \mathrm{m}^{2}$ ) (Table 1). A total of 84 PEEK cages were performed. There were 12 fusions at the L3-L4 level, 36 fusions of the L4-L5 level and 36 fusions of the L5-S1
Table 1 Characteristics of the patient population

\begin{tabular}{ll}
\hline $\begin{array}{l}\text { Number of patients } \\
\text { Gender }\end{array}$ & 40 \\
Males & $5(12.5 \%)$ \\
Females & $35(87.5 \%)$ \\
Age, years & $67 \pm 9$ \\
BMI & $26.4 \pm 5.2$ \\
Follow-up (months) & $27.5 \pm 9.5$ \\
\hline
\end{tabular}

Table 2 Number of levels fused

\begin{tabular}{lr}
\hline Levels of PEEK cage usage & 84 \\
Patients who had 1-level fusion & 7 \\
Patients who had 2-level fusion & 22 \\
Patients who had 3-level fusion & 11 \\
Posterior fusion level numbers & 7 \\
4 levels & 2 \\
5 levels & 4 \\
6 levels & 27 \\
More than 6 levels & \\
\hline
\end{tabular}

level. Additional posterior long fusion was performed. There were seven cases of 4 levels, two cases of 5 levels, four cases of 6 levels, and 27 cases of more than 6 levels (Table 2).

Harvested vertebral height

The harvested adjacent vertebral body was measured immediately postoperatively and at the final follow-up. There were $10 \mathrm{~L} 3,34 \mathrm{~L} 4$ and 39 L5 sites. The L3 vertebral height was $32.9 \pm 5.4$ and $32.1 \pm 5.2 \mathrm{~mm}$ postoperatively and at the final follow-up, respectively $(p>0.05)$. The L4 vertebral height was $31.0 \pm 5.2$ and $30.7 \pm 4.9$ postoperatively and at the final follow-up, respectively $(p>0.05)$. L5 vertebral height was $29.0 \pm 4.9$ and $28.7 \pm 4.7$ postoperatively and at the final follow-up, respectively $(p>0.05)$ (Fig. 4). There were no harvesting-related or allograft bone (from the Synthes Corporation)-related complications. There was no significant weakening of adjacent vertebrae caused by local bone harvest.

\section{Segmental lordosis}

After PEEK cage implantation, the segmental lordosis of the L3-L4 level was increased from $11.2^{\circ} \pm 7.8^{\circ}$ preoperatively to $18.8^{\circ} \pm 6.7^{\circ}$ immediately postoperatively $(p<0.05)$. The segmental lordosis of L4-L5 was also significantly $(p<0.05)$ increased from $16.1^{\circ} \pm 11^{\circ}$ preoperatively to $21.1^{\circ} \pm 8.4^{\circ}$ immediately postoperatively $(p<0.05)$. The segmental lordosis of the L5-S1 level was 
increased from $16.1^{\circ} \pm 7.6^{\circ}$ preoperatively to $19.9^{\circ} \pm 6.4^{\circ}$ immediately postoperatively $(p<0.05)$. The final followup lordosis was also increased compared with the preoperative lordosis, but there was no significant difference $(p>0.05)$ (Table 3).

Fusion and subsidence rates

The fusion rates using PEEK cages were 44.0 and $96.4 \%$ at 3 months and final follow-up, respectively. The subsidence rates were 1.2 and $8.3 \%$ at 3 months and final follow-up, respectively (Fig. 5). The disc space height with PEEK cages was decreased at final follow-up compared to immediately postoperatively. The L3-L4, L4-L5 and L5-S1 space heights were decreased by $0.59,0.33$ and $0.53 \mathrm{~mm}$, respectively $(p<0.05)$ (Table 3).

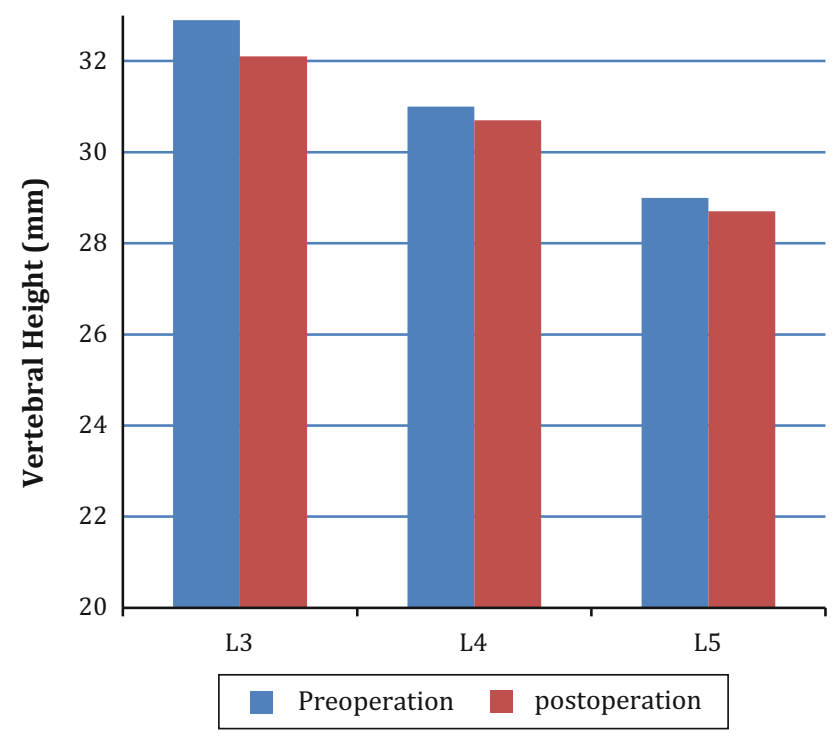

Fig. 4 Harvested vertebra height
Evaluation of PEEK cage migration

The distance from the anterior rim of the PEEK cages to the anterior margin of the spine vertebra was measured immediately postoperatively and at the final follow-up. The distances of PEEK cages in L3-L4, L4-L5, and L5-S1 were shortened by $0.83,0.36$ and $0.55 \mathrm{~mm}$ at final followup, respectively (Fig. 6).

\section{Complications}

There were no major complications such as infection, vertebral compression fracture, pseudarthrosis and graft collapse after ALIF using PEEK cages at the final followup. One patient underwent revision surgery because the proximal hooks had dislodged from their fixation points. This movement caused the rods and the hooks to display prominence (Table 4).

\section{Discussion}

Posterior long fusion is a traditional method to correct spinal deformity that involves the lumbosacral injunction or structural abnormities such as advanced degeneration or lumbosacral instability. Supplemental ALIF using structural interbody grafting of the lower lumbar spine and lumbosacral segments aims to maximize the fusion rate, improve sagittal balance and prevent implant failure across the lumbosacral junction [4, 20, 21]. It can also distract the disc space and facilitate intervertebral foramen decompression by increasing the spinal canal diameter [22].

\section{Harvested vertebrae}

The objective of a lumbar fusion is to create an environment that will allow bone to form a solid osseous bridge across the involved spinal segments. Autologous iliac crest bone (AICB) is the gold standard because of its ideal graft

Table 3 Segmental lordosis and fusion rate

\begin{tabular}{llllll}
\hline & $N$ & Preop & Postop & 3 months & Final follow-up \\
\hline Segmental lordosis & & & & & \\
L3-L4 & 12 & $11.2 \pm 7.8$ & $18.8 \pm 6.7$ & $17.5 \pm 5.5$ & $15.8 \pm 7.1$ \\
L4-L5 & 36 & $16.1 \pm 11$ & $21.1 \pm 8.4$ & $21.2 \pm 9.3$ & $17.8 \pm 7.5$ \\
L5-S1 & 36 & $16.1 \pm 7.6$ & $19.9 \pm 6.4$ & $20.1 \pm 7.8$ & $16.9 \pm 6.5$ \\
Upper to end vertebra (one level is not included) & 33 & $30.5 \pm 12.3$ & $39.9 \pm 10.7$ & $38.8 \pm 13.1$ & $36.8 \pm 10.3$ \\
T12-S1 & 40 & $35.1 \pm 15.9$ & $47.2 \pm 11.2$ & $46.4 \pm 10.2$ & $42.6 \pm 9.9$ \\
Fusion rate & 84 & & & $37(44 \%)$ & $81(96.4 \%)$ \\
Subsidence rate & 84 & & & & \\
\hline
\end{tabular}

$N$ numbers 


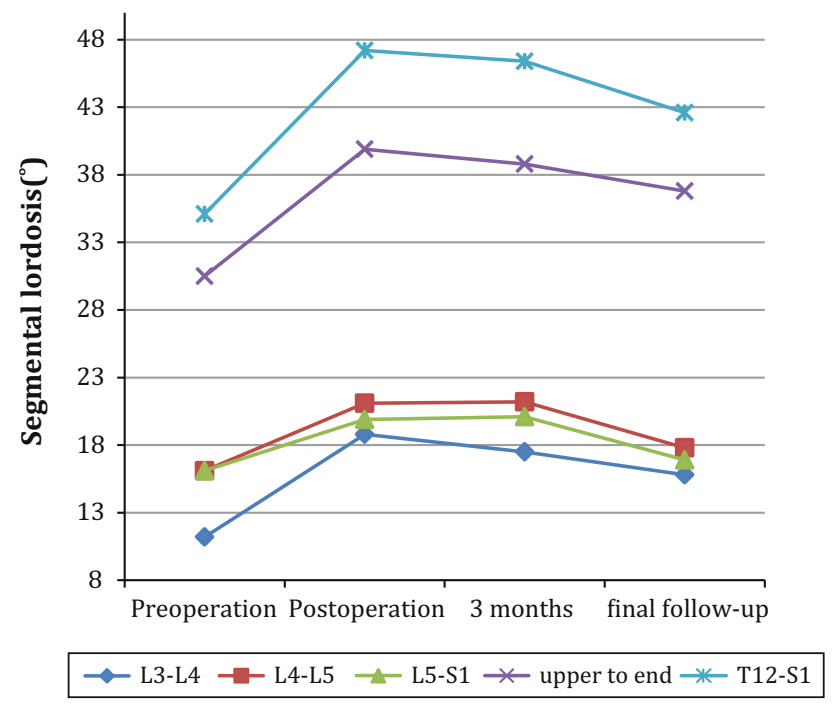

Fig. 5 Segmental lordosis

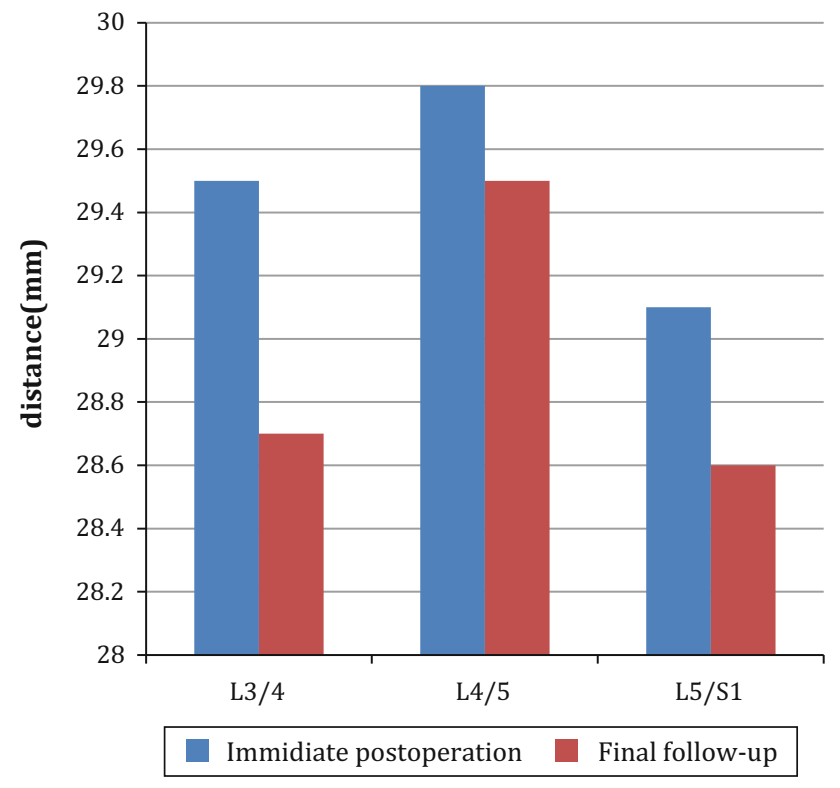

Fig. 6 PEEK cages migration

characteristics including osteoconduction, osteoinduction, and osteogenesis [23-25]. However, harvesting AICB is commonly associated with increased postoperative pain and this may be underestimated by the treating surgeon $[26,27]$. Additional drawbacks of AICB include limited supply and increased operative time and blood loss. There are numerous studies demonstrating the fusion potential of BMPs [28, 29]. However, complications associated with their use have been reported $[25,30,31]$. It is unclear whether the benefits of BMPs justify the costs.

Locally harvested autograft is one potential candidate. Cancellous nonstructural bone may be harvested from the anterior aspect of the vertebral bodies. This approach avoids the costs of a bone substitute and reduces the complications associated with the iliac crest. In the current study, we evaluated the vertebral height change after removing a cylindrical bone plug from the anterior aspect of the vertebrae. The heights of L3, L4 and L5 were $32.9 \pm 5.4,31.0 \pm 5.2$, and $29.0 \pm 4.9 \mathrm{~mm}$ at the immediate postoperative measurement, respectively. The values were $32.1 \pm 5.2,30.7 \pm 4.9$, and $28.7 \pm 4.7 \mathrm{~mm}$ at final follow-up, respectively. There were no significant differences. Consistent with our results, Tobias Pitzen [32] investigated the immediate mechanical response of the cervical spine after removing bone from the central vertebral body. The study concluded that there was no significant early biomechanical weakening of adjacent vertebrae caused by the aforementioned technique of local bone harvest. Steffen et al. [33] evaluated the effect of removing a bone plug from the lumbar vertebra in different studies and found that regional bone graft harvest in anterior spine surgery is anatomically safe and biomechanically acceptable. Arlet et al. [34] described preliminary clinical results using the technique and found limited intraoperative complications, good clinical results, and fusion in all of the cases.

Fusion

In our study, fusion rates using PEEK cages were 44.0 and $96.4 \%$ at 3 months and final follow-up, respectively. The lack of evidence of pseudarthrosis, radiolucencies, and motion on radiographs coupled with the good outcomes suggests that the motion segments were stable and fused according to more inclusive standards. The absence of changes in radiographic does not necessarily mean that a fusion is achieved. It just helped to indicate it. Previous studies have reported similarly high fusion rates of PEEK
Table 4 Disc space height

$I$ immediate postoperation, $F$ final follow-up

\begin{tabular}{|c|c|c|c|c|c|c|}
\hline \multirow[t]{2}{*}{ Disc space } & \multicolumn{2}{|c|}{$\mathrm{L} 3 / 4(n=12)$} & \multicolumn{2}{|c|}{$\mathrm{L} 4 / 5(n=34)$} & \multicolumn{2}{|c|}{$\mathrm{L} 5 / \mathrm{S} 1(n=39)$} \\
\hline & $I$ & $F$ & $I$ & $F$ & $I$ & $F$ \\
\hline Height (mm) & $12.8 \pm 2.9$ & $11.8 \pm 2.9$ & $12.7 \pm 2.3$ & $12.4 \pm 2.1$ & $11.8 \pm 2.1$ & $11.3 \pm 2.0$ \\
\hline$t$ & 8.03 & & 3.35 & & 7.95 & \\
\hline$p$ & 0.001 & & 0.002 & & 0.000 & \\
\hline
\end{tabular}


cages $[13,14,35](76-100 \%)$. Brantigan et al. [36] reported that $45 \%$ of PEEK cages achieved solid fusion at 3 months and that $96 \%$ had fusion at 1 year. Tullberg et al. [37] reported that the lumbar interbody solid fusion rate was $89 \%$ using PEEK cages at a minimum 1-year follow-up.

\section{Subsidence}

Eighty-four vertebral levels were evaluated, and seven levels of implant subsidence into the adjacent vertebra occurred in our cohort $(8.3 \%)$. Similar findings were reported by Eyal Behrbalk et al. [38] who found a $16 \%$ subsidence rate using the stand-alone anterior lumbar interbody fusion with PEEK cages at $17 \pm 6$ months follow-up. The subsidence rate was reported as $25 \%$ in other series $[39,40]$.

Our lower subsidence rate may be explained by the locally harvested bone and additional posterior fusion. We did not measure the increment of disc space height because all previous studies have shown that ALIF using PEEK can significantly increase the disc space [13, 38, 41]. Our study revealed a significant space height loss immediately postoperatively and at the final follow-up. Similar findings reported that a majority of segments lose disc space height during the postoperative period [29]. The loss is probably due to spacer subsidence, graft resorption or collapse and bone fusion processing [41, 42].

\section{Segmental lordosis}

Polyetheretherketone cages maintained a significant increase in segmental lordosis at all postoperative intervals, but it was still reduced by $3.58^{\circ}$ in L3-L4, $3.67^{\circ}$ in L4-L5 and $3.97^{\circ}$ in $\mathrm{L} 5 / \mathrm{S} 1$ at the final follow-up $(p<0.05)$. Consistent with our results, Liljenqvist et al. [43] observed that FRA implantation had $56.7 \%$ (or $1.7^{\circ}$ ) loss at the 6-month follow-up when combined with postoperative instrumentation. Rousseau et al. [35] observed that the segmental lordosis loss was significantly related to the increase in postoperative lordosis, cage height, rigid posterior instrumentation, lower levels, and the order of the posterior and anterior combined procedures.

\section{Cage migration}

Cage migration was defined as the movement of the cage into the spinal canal either posterior or anterior. One novel and particularly intriguing observation in this study is that PEEK cages had a tendency to move forward. The migration distances of PEEK cages at the final follow-up were $0.83,0.36$ and $0.55 \mathrm{~mm}$, respectively. There were no cases with large movements. Although it was a small change, there was a significant difference $(p<0.05)$. Kuslich et al. [44] showed that implant migration was correlated with several intraoperative situations including small cage size, inadequate seating of the cage anteriorly, lack of posterior instrumentation and striping of bone threads. In the current study, cage migration was more closely correlated to the destruction of the anterior longitudinal ligament and the anterior portion of the anterior annulus fibrosus. Interestingly, no symptoms accompanying cage migration were found. This result might be explained by the direction of the cage movement.

Our study had several potential limitations. First, it was a retrospective study with a limited cohort and there was no control group. Second, we only evaluated the radiographic efficiencies of PEEK cages for ALIF because posterior long fusion status was difficult to evaluate. Third, the height of harvested sacrum was ignored as it was difficult to measure. Finally, we only evaluated the height of locally harvested vertebrae, and the complete physiological loading scenario was not known and cyclic loading was not performed. Thus, additional biomechanical laboratory investigations are required to support the results.

In conclusion, PEEK cages with local vertebral autograft for spinal deformity fusion to the low lumbar spine can get $96.4 \%$ interbody fusion rate and $8.3 \%$ subsidence rate, which is comparable with other published series. The segmental lordosis had a tendency to lose. The allograft is safe and effective in maintaining the harvested vertebra shape. No related complication occurred. The PEEK cages had a tendency to migrate forward. However, long-term follow-up study is needed to justify the outcome.

\section{Conflict of interest None.}

Open Access This article is distributed under the terms of the Creative Commons Attribution License which permits any use, distribution, and reproduction in any medium, provided the original author(s) and the source are credited.

\section{References}

1. Flynn JC, Hoque MA (1979) Anterior fusion of the lumbar spine. End-result study with long-term follow-up. J Bone Joint Surg Am 61(8):1143-1150

2. Burkus JK et al (2002) Anterior lumbar interbody fusion using rhBMP-2 with tapered interbody cages. J Spinal Disord Tech 15(5):337-349

3. Stauffer RN, Coventry MB (1972) Anterior interbody lumbar spine fusion. Analysis of Mayo Clinic series. J Bone Joint Surg Am 54(4):756-768

4. Bradford DS, Tay BK, Hu SS (1999) Adult scoliosis: surgical indications, operative management, complications, and outcomes. Spine (Phila Pa 1976) 24:2617-2629

5. Bridwell KH, Lenke LG, McEnery KW et al (1995) Anterior fresh frozen structural allografts in the thoracic and lumbar spine. Do they work if combined with posterior fusion and 
instrumentation in adult patients with kyphosis or anterior column defects? Spine (Phila Pa 1976) 20:1410-1418

6. Kleinstueck FS, Hu SS, Bradford DS (2002) Use of allograft femoral rings for spinal deformity in adults. Clin Orthop Relat Res 394:84-91

7. Kuzhupilly RR, Lieberman IH, McLain RF et al (2002) In vitro stability of FRA spacers with integrated crossed screws for anterior lumbar interbody fusion. Spine (Phila Pa 1976) 27:923-928

8. Cain CM, Schleicher P, Gerlach R, Pflugmacher R, Scholz M, Kandziora F (2005) A new stand-alone anterior lumbar interbody fusion device: biomechanical comparison with established fixation techniques. Spine 30:2631-2636

9. Schimmel JJ et al (2012) PEEK cages in lumbar fusion: midterm clinical outcome and radiological fusion. J Spinal Disord Tech. doi:10.1097/BSD.0b013e31826eaf74

10. Galbusera F, Schmidt H, Wilke H-J (2012) Lumbar interbody fusion: a parametric investigation of a novel cage design with and without posterior instrumentation. Eur Spine J 21(3):455-462

11. Blumenthal SL, Gill K (1993) Can lumbar spine radiographs accurately determine fusion in postoperative patients? Correlation of routine radiographs with a second surgical look at lumbar fusions. Spine (Phila Pa 1976) 18(9):1186-1189

12. McAfee PC et al (2001) Symposium: a critical discrepancy-a criteria of successful arthrodesis following interbody spinal fusions. Spine (Phila Pa 1976) 26(3):320-334

13. McAfee PC, DeVine JG, Chaput CD et al (2005) The indications for interbody fusion cages in the treatment of spondylolisthesis: analysis of 120 cases. Spine (Phila Pa 1976) 30:S60-S65

14. Cutler AR, Siddiqui S, Mohan AL et al (2006) Comparison of polyetheretherketone cages with femoral cortical bone allograft as a single-piece interbody spacer in transforaminal lumbar interbody fusion. J Neurosurg Spine 5:534-539

15. Crandall DG, Revella J (2009) Transforaminal lumbar interbody fusion versus anterior lumbar interbody fusion as an adjunct to posterior instrumented correction of degenerative lumbar scoliosis: three year clinical and radiographic outcomes. Spine (Phila Pa 1976) 34:2126-2133

16. Anand N, Baron EM, Thaiyananthan G et al (2008) Minimally invasive multilevel percutaneous correction and fusion for adult lumbar degenerative scoliosis: a technique and feasibility study. J Spinal Disord Tech 21:459-467

17. Strube $P$ et al (2012) Stand-alone anterior versus anteroposterior lumbar interbody single-level fusion after a mean follow-up of 41 months. J Spinal Disord Tech 25(7):362-369

18. Brantigan JW et al (2000) Lumbar interbody fusion using the Brantigan I/F cage for posterior lumbar interbody fusion and the variable pedicle screw placement system: two-year results from a Food and Drug Administration investigational device exemption clinical trial. Spine (Phila Pa 1976) 25(11):1437-1446

19. Burkus JK et al (2009) Six-year outcomes of anterior lumbar interbody arthrodesis with use of interbody fusion cages and recombinant human bone morphogenetic protein-2. J Bone Joint Surg Am 91(5):1181-1189

20. Buttermann GR, Glazer PA, Hu SS et al (1997) Revision of failed lumbar fusions. A comparison of anterior autograft and allograft. Spine (Phila Pa 1976) 22:2748-2755

21. Perra JH (1994) Techniques of instrumentation in long fusions to the sacrum. Orthop Clin North Am 25:287-299

22. Dennis S, Watkins R, Landaker S et al (1989) Comparison of disc space heights after anterior lumbar interbody fusion. Spine (Phila Pa 1976) 14:876-878

23. Banwart JC, Asher MA, Hassanein RS (1995) Iliac crest bone graft harvest donor site morbidity. A statistical evaluation. Spine (Phila Pa 1976) 20:1055-1060
24. Goldberg VM, Stevenson S (1987) Natural history of autografts and allografts. Clin Orthop Relat Res 225:7-16

25. Haid RW Jr, Branch CL Jr, Alexander JT, Burkus JK (2004) Posterior lumbar interbody fusion using recombinant human bone morphogenetic protein type 2 with cylindrical interbody cages. Spine J 4:527-539

26. Heary RF, Schlenk RP, Sacchieri TA, Barone D, Brotea C (2002) Persistent iliac crest donor site pain: independent outcome assessment. Neurosurgery 50:510-517

27. Kanayama M, Hashimoto T, Shigenobu K, Yamane S, Bauer TW, Togawa D (2006) A prospective randomized study of posterolateral lumbar fusion using osteogenic protein-1 (OP-1) versus local autograft with ceramic bone substitute: emphasis of surgical exploration and histologic assessment. Spine (Phila Pa 1976) 31:1067-1074

28. Burkus JK, Gornet MF, Schuler TC, Kleeman TJ, Zdeblick TA (2009) Six-year outcomes of anterior lumbar interbody arthrodesis with use of interbody fusion cages and recombinant human bone morphogenetic protein-2. J Bone Joint Surg Am 91:1181-1189

29. Delawi D, Dhert WJ, Rillardon L, Gay E, Prestamburgo D, Garcia-Fernandez C et al (2010) A prospective, randomized, controlled, multicenter study of osteogenic protein-1 in instrumented posterolateral fusions: report on safety and feasibility. Spine (Phila Pa 1976) 35:1185-1191

30. Pradhan BB, Bae HW, Dawson EG, Patel VV, Delamarter RB (2006) Graft resorption with the use of bone morphogenetic protein: lessons from anterior lumbar interbody fusion using femoral ring allografts and recombinant human bone morphogenetic protein-2. Spine (Phila Pa 1976) 31:E277-E284

31. Rihn JA, Patel R, Makda J, Hong J, Anderson DG, Vaccaro AR et al (2009) Complications associated with single-level transforaminal lumbar interbody fusion. Spine J 9:623-629

32. Pitzen T, Tan JS, Dvorak MF, Fisher C, Oxland T (2012) Local autograft retrieval from a cervical vertebral body: biomechanical consequences. J Neurosurg Spine. 16(4):340-344

33. Steffen T, Downer P, Steiner B, Hehli M, Aebi M (2000) Minimally invasive bone harvesting tools. Eur Spine J 9(Suppl 1):S114-S118

34. Arlet V, Jiang L, Steffen T, Ouellet J, Reindl R, Aebi M (2006) Harvesting local cylinder autograft from adjacent vertebral body for anterior lumbar interbody fusion: surgical technique, operative feasibility and preliminary clinical results. Eur Spine J 15:1352-1359

35. Rousseau MA, Lazennec JY, Saillant G (2007) Circumferential arthrodesis using PEEK cages at the lumbar spine. J Spinal Disord Tech 20:278-281

36. Brantigan JW, Steffee AD, Lewis ML et al (2000) Lumbar interbody fusion using the Brantigan $\mathrm{I} / \mathrm{F}$ cage for posterior lumbar interbody fusion and the variable pedicle screw placement system: two-year results from a Food and Drug Administration investigational device exemption clinical trial. Spine (Phila Pa1976) 25:1437-1446

37. Tullberg T, Brandt B, Rydberg J et al (1996) Fusion rate after posterior lumbar interbody fusion with carbon fiber implant: 1-year follow-up of 51 patients. Eur Spine J 5:178-182

38. Behrbalk E, Uri O, Parks RM, Musson R, Soh RC, Boszczyk BM (2013) Fusion and subsidence rate of stand alone anterior lumbar interbody fusion using PEEK cage with recombinant human bone morphogenetic protein-2. Eur Spine J 22(12): 2869-2875

39. Carragee EJ, Hurwitz EL, Weiner BK (2011) A critical review of recombinant human bone morphogenetic protein-2 trials in spinal surgery: emerging safety concerns and lessons learned. Spine J 11(6):471-491 
40. Mroz TE et al (2010) Complications related to osteobiologics use in spine surgery: a systematic review. Spine 35(9S):S86-S104

41. Kumar A, Kozak JA, Doherty BJ et al (1993) Interspace distraction and graft subsidence after anterior lumbar fusion with femoral strut allograft. Spine (Phila Pa 1976) 18:2393-2400

42. Carter JD, Swearingen AB, Chaput CD, Rahm MD (2009) Clinical and radiographic assessment of transforaminal lumbar interbody fusion using HEALOS collagen-hydroxyapatite sponge with autologous bone marrow aspirate. Spine J 9:434-438
43. Liljenqvist U, O’Brien JP, Renton P (1998) Simultaneous combined anterior and posterior lumbar fusion with femoral cortical allograft. Eur Spine J 7:125-131

44. Kuslich SD, Ulstrom CL, Griffith SL et al (1998) The Bagby and Kuslich method of lumbar interbody fusion: history, techniques, and 2-year follow-up results of a United States prospective, multicenter trial. Spine 23:1267-1278 